\title{
Der Ursprung der interstitiellen Zellen des Ovariums beim Hunde.
}

\author{
Von \\ R. Tsukaguchi und T. Okamoto. \\ Aus dem Anatomischen Institut zu Osaka.
}

Mit 12 Textfiguren.

In der reichen Literatur über den Ursprung der sog. interstitiellen Drüse Limon's des Eierstocks wird die Anmahme als am meisten zuverlässig hervorgehoben, nach welcher die Wucherung der inneren Thecazellen eines atretischen Follikels ibre Entstehung fertigbringt. Es liegen die Beobachtungen von Limon, Cohn, Fränkel, Schaeffer u.a.m. an Menschen, Nagem, Chiropteren, Insektivoren und Karnivoren zu Grunde. Thre Ausbildung ist allerdings je nach den Tierarten äusserst verschieden. Es bedarf demzufolge zuweilen für ihre Entstehung eincr ganz anderweitigen Deutung. Nämlich, Fränkel beschreibt ihre Ähnlichkeit mit den Marksträngen, die am Hilusteil Platz finden, auch Seitz konstatiert an verschiedenen Stellen ihren Übergang in die Stromazellen, was ihn zu der Annahme berechtigt, dass es bei ihrer Entstehung einen zweiten Modus gäbe.

Die interstitielle Drüse entwickelt sich bei der Hündin unter Umständẹn ganz gut, wie bekannt. Da hier keine Wucherung der inneren Thecazellen bei einer Follikelatresie zustande kommt, ja sogar die Thecazellen selbst nur wenig ausgeprägt erscheinen, wie Schmaltz geschildert hat, sollte man auch hier ihre Entstehung ganz anderweitig zu erklären versuchen. Diesbezüglich kommen unsere Untersuchungen dem eben angeführten Resultat Seitz's sehr nahe, wonach sie ausschliesslich von Stromazellen genetisch abgeleitet werden mag. Nun fragt es sich, woher die Stromazellen kommen, was für eine Art von Zellen sie sind. Ohne 
dies klarzustellen, wäre es selbstredend nicht möglich, den Ursprung der interstitiellen Drüse aufzuklären. Die vorliegende Arbeit beabsichtigt deswegen hauptsächlich die Erforschung der Herstammung der Stromazellen im allgemeinen anstatt der interstitiellen Drüse.

Dass das Eierstockstroma als kein einfaches Bindegewebe angesehen werden darf, ist von manchem anerkannt. Es war schon in frühester Zeit fraglich, ob es aus glattem Muskelgewebe besteht. Kölliker ist der erste, der einen Gehalt an diesem bestritten hat. Seine Anschauung wurde von der späteren Forschung immer mehr bestätigt und jetzt ist man ganz allgemein der Meinung, dass es sich schliesslich etwa um eine spezielle Art Bindegewebe handle, was die meisten grossen Bücher wie von Kölliker, Ellenborger, Prenannt et Bouin, Halban und Seitz u.a.m. kemntlich machen. Man lässt infolgedessen den inneren Thecazellen (Kornzellen), als besonderer Form der Stromazellen, ebenso wie den von ihnen abzuleitenden interstitiellen Zellen dieselbe bindegewebige Natur zukommen. Es kommt jedoch keineswegs vor, dass die histogenetische Beweisführung, es für bindegewebig halten zu müssen, von jemand unumstösslich bewiesen wurde. Um hiervon etwas fester zu überzeugen, möchten wir auf die bisherigen histogenetischen Untersuchungen, welche Schulin, Mihalkovics, Nagel, Janosik, Coert, Skrobansky, Allen, Whitehead u.a. an Menschen, Kaninchen, Katzen, Schafen und Schweinen angestellt haben, Rücksicht nehmen und die Ergebnisse, die sie gemein haben, nur in kurzen Zügen hier wiedergeben.

In der geschlechtlich noch nicht differenzierten frühesten Zeit der Entwickelung ist die Keimdrüsenanlage nichts anderes als eine einfache Verdickung des Keimepithels, und es ist da noch von keinem Mesenchym zu sprechen. In der folgenden Zeit, wo die Embryonen sich weiter entwickehn und sich geschlechtlich unterscheiden lassen, zeigt das Keimepithel des Eierstockes nicht nur starke Wucherung, sondern auch den ersten Anfang der Differenzierung eines gewissen Interstitiums, durch welches die Keimschicht allmählich in Keimstränge geteilt wird. Die letzteren bilden später selbstverständlich die Rindensubstanz aus. Als ein zweites Bauelement des Eierstockes kommen die Retestränge hinzu, welche zu ciner früheren Zeit gleich dem Epithel der Leibeshöhle an einem etwas mehr kranialen Körpersegmente (Reteblastem) ihren Ursprung finden. Sie lassen die Markstränge sich caudal entfalten, um die Entwickelung der Marksubstanz zu vervollständigen. Nun ist der Eierstock hauptsächlich durch epitheliale Elemente fast definitiv angelegt. Was aber die Bildung des Stromagewebes anlangt, so ist in ler aller- 
frühesten Zeit der Keimdrüsen-Entwickelung, wie erwähnt, noch keineswegs davon zu sprechen. Den ersten Beginn der Stromabildung, die in der nächsten Zeit innerhalb der Keimschicht vor sich geht, lassen Schuliu wie Coert vom Keimepithel ausgehen, demn die Bildung des Mesenchyms seitens des Mesonephros kommt erst in einer späteren Periode zustande, und es wächst sogar das diesbezügliche Element nach Nagel u. Coert nicht besonders. Im Gegensatz dazu erfolgt die Wucherung des Stromagewebes, nach den Beobachtungen von Coert, Allen und Whitehead, immer beständig aus der Proliferation der Kölombekleidung der Keimdrüse. Unter anderem ist Coert der Ansicht, dass die bindegewebigen Hüllen der Keimstränge unmittelbar von diesen gebildet werden und somit in der Mesenchymbildung zur Zeit ein doppelter Modus bestehen muss.

Aus der obigen zusammenfassenden Betrachtung über die meisten histogenetischen Forschungsergebnisse lässt sich ohne weiteres der Schluss ziehen, dass das ganze Bauelement, woraus der Eierstock besteht, epithelial angelegt ist, abgesehen von nur geringer Menge Bindegewebe, das von Mesonephros stammt. Es ist ganz merkwürdig, lass man trotz der obigen Schlussfolgerung allgemein mit dem Gedanken umgeht, das Eierstockstroma, wie erwähnt, ausschliesslich für bindegewebig zn erklären. Um in solchen Meinungsirrtum nicht zu verfallen, , bedarf es unseres Erachtens noch einer weiteren, eingehenderen Verfolgung einzelner Bauelemente vom intrauterinen Stadium bis zum postembryonalen. Man sollte dabei besonders auf die Markstränge Gewicht legen und ihr Schicksal genau beobachten, denn die Keimstränge, das eine von den beiden Hauptbauelementen, sind allbekannterweise fast ausschliesslich für die Follikelausbildung bestimmt, während die Markstränge dagegen in ihrer Ausbildung sehr wechselnd und in ihrer Bedeutung noch ganz rätselhaft sind. Die Markstränge treten im allgemeinen in der embryonalen Zeit am deutlichsten hervor, nach der Geburt hingegen meist gleich in den Hintergrund bis zum totalen Schwund. Nach Bühler erreichen sie beim Kaninchen am 24. embryonalen Tage den Höhepunkt der Entwickelung und verschwinden schon wenige Tage nach der Geburt sehr bald. Fast das gleiche gilt auch beim Menschen und Pferd. Bei bestimmten Tieren werden sie dagegen beibehalten, wozu zum ersten Karnivoren, dann Insektivoren gehören. An solchen Tieren zeichnen sie sich im Eierstockstroma, wie bekannt, als eigentümlichen Bestand aus, dessen Erscheinungsweise je nach den Tierarten ja sogar nach den Individuen und dem Alter gar nicht dieselbe zu sein scheint.

Das Stromagewebe des Eierstocks entwickelt sich bei Neugeborenen 
des Menschen und des Kaninchens eimerseits schon ziemlich gut, wo die Markstränge meist in Rückgang getreten sind. Bei der Hündin (so auch Karnivoren), wo sie lange bestehen, ist anderseits die Markzone fast ausschliesslich durch sie selbst und Zellmengen als deren Abkömmling, also nur noch epithelial zusammengesetzt. An eigentlichem Bindegewebo ist da am wenigsten anzutreffen.

Diese widersprechend scheinende Sachlage ist es, die einen wohl auf die Vermutung kommen lässt, es existiere irgendeine genetische Beziehung zwischen Marksträngen und Stromagewebe. Da in den Marksträngen zuweilen Eier auftreten, hat man keinen Grund zu bezweifeln, dass jene teilwcise zur Follikelbildung verbraucht werden. Aber nur teilweise, vom übrigen Teil weiss man nichts bestimmtes. Nach Schaeffer verfällt es schliesslich in Degeneration und verschwindet, Bühler sieht die Markstränge bei einem 9 monatlichen Fötus in die Eiballen der Rinde eindringen, olne ihr weiteres Schicksal fostzustellen. Tsukaguchi untersuchte, in welcher Weise der Markstrang beim Kaninchen in postembryonaler ' 'heit zurücktritt und komnte seine Spur noch bei einem 3 Monate alten Jungen vorfinden und sah den Grund zu seinem steten Schwund darin, dass sein Element allmählich sich zerstreuend in die Stromazcllen übergeht. Er fand ferner bei cinem neugeborenen Menschen ein gewisses Markstrangelement nach der Wand eines schon ziemlich entwickclten Folliculus vesiculosus sich hinziehen, um sich da wohl in Thecazellen umzuwandeln. Im Anschluss an solche Beobachtungen hatte er gleich einige Befunde auch an Hündinnen und Katzen und wurde schliesslich zu der Voraussetzung geführt, die Stromazellen ständen mit den Marksträngen genetisch in inniger Beziehung. Es handelt sich daher bei dieser Publikation gar nicht darum, hiermit etwas Neues an den Tag zu bringen. Es ist unsere Absicht, dass der Ursprung und Ausgang der Markstränge, beziehungsweise die genetisch-histologischen Einzelheiten in bezug auf Stromazellen respektiv interstitielle Drüse klargelegt werden möchten, wobei wir zum Material die Hündin gewählt haben, bei welcher die Markstränge meist in hohem Grade auftreten. Ihr Werdegang wurde in verschiedenen Wachstumszeiten rom Neugeborenen bis zum Erwachsenen systematisch untersucht. Unser Resultat dürfte wohl zur Entscheidung der Markstrangfrage etwas beitragen.

\section{Das Material und die Methode.}

Die $3,10,14,17,20,23,25,27,30,45$ und 60 Tagc alten Jungen der Hündin und je ein halbes Jahr, ein Jahr, anderthalb Jahre alte 
und ganz erwachsene, mindestens einmal geworfen habende Hündinnen. sind uns als Untersuchungsmaterial zur Verfügung gestcllt. Jedem Tiere wurde unter der tiefen Chloroformnarkose die Bauchhöhle geöffnet und zuerst das äussere V(rhältnis des Uterus und der Adnexe makroskopisch untersucht. Dor Eierstock wurde dam beiderseits exstirpiert und in die Fixierungsflüssionkeit eingelegt. Als solche haben wir meistens dis: Orth'sche Flüssigkeit benützt.

Die Flüssigkeit von Meves, Levi, Luna etc. hat auch zu besonderen Zwecken wie bei der Granulaforschung ihre lnwendung gefunden.

Nach Paraffin-Einbettung sind Serienschnitte von allen Stücken angefertigt. Die Doppelfärbung nit Hämatoxylin nach Hansen und Eosin sowie dic Eisenhämatoxylinmethode sind zumeist verwendet.

\section{Eigene Beobaclitung.}

Hier beschreiben wir von jedem Alter hauptsächlich die genetischen Verhältnisse des Eierstockstromas, dessen Elemente mit der Entwickelung der Tiere gewisse Änderungen erfahren.

3 Tage alt. (Bezeichn. H. 58. Eine Art Hühnerhund.

21. IV. 1925.)

Das Keimepithel lässt sich von der Unterlage durch eine düme Bindegewebsschicht, sog. primäre Albuginea, gut abgrenzen. Es kommt doch vor, dass es in Form von Epithelzapfen resp. -strängen hie und da in die Rinde hineindringt. Sie nähern sich den Keimsträngen und kömmen sich sogar oft mit diesen unmittelbar verbinden. Am meisten machen sich jedoch ihre Elemente von ihrem apithelialen V'erband los, um sich in das Rindenstroma zu verstreuen.

Den Hauptbestandteil der Rinde bilden selbstredend die Keimstränge, welche durch das nur spärliche Stromagewebe roneinander geschieden sind. Sie haben augenscheinlich keine besondere Grenzhülle, lassen sich nichtsdestoweniger von dem ebenfalls meist noch zellulären Stroma ganz deutlich unterscheiden, indem die besondere Grösse und Gestalt ihrer Elemente massgebend ist. Das Rindenstroma besteht keineswegs aus blossem Bindegewebe, sondern enthält viel Zellelement. Fin nur geringer Teil von diesen sind sicherlich gemeine bindegewebige Zellen, während sie grösstenteils nach genauer Untersuchung in Bezug auf ihre Form und Grösse sich ganz anders verhalten, sodass mau sie als „, Stromazellen“", wie wir sie hier nennen, von jenen scharf unterscheiden kann. Sie zeichmen sich im Vergleiche mit den. bindegewebigen Zellen 
durch den Besitz eines runden oder ovalen, mehr oder minder grossen Kernes aus und können oft mit den Elementen der oben geschilderten Keimepithelzapfen einer- und dor Keimstränge anderseits ohne weiteres zusammenhängen. Die diesbezügliche Sachlage bringt uns ungezwungen zur Annahme ihrer epithelialen Abkunft.

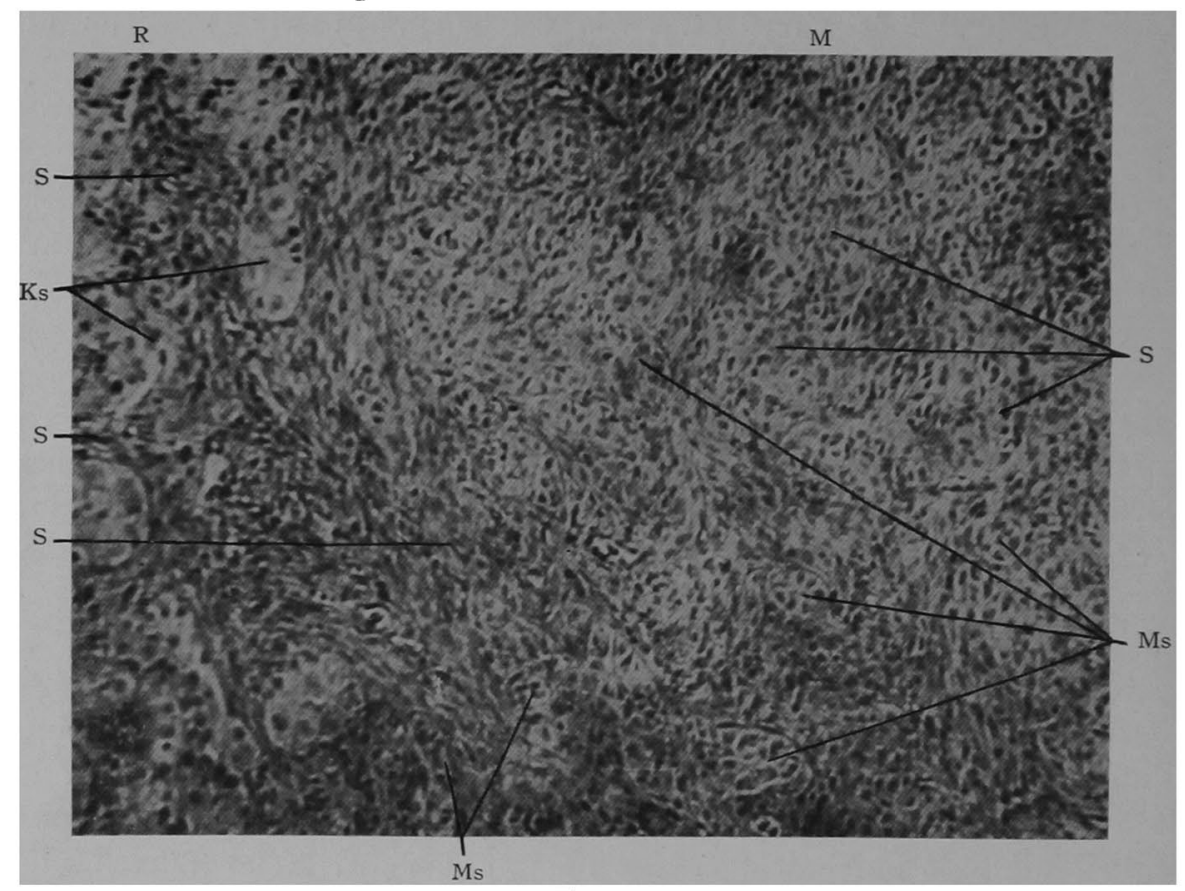

Fig. 1.

; Tage alt. $190 \times$

Ks Keimstrang. Ms Markstrang. II Mark. R Rinde. is Stromagewebe.

Das Markgewebe ist sehr reichlich und durch Zellreichtum charakterisiert. Das faserige Bindegewebe ist darin nur sehr spärlich. Die Markstränge finden sich auch sehr reichlich als solide Zellstränge verschiedener Dicke. Sie kommen stellenweise äusserst viel in Gruppen ror, wo sie die Hauptmasse des Markes bilden. In der betreffenden Stelle kann die Begrenzung einzelner Markstränge zum Teil fast ganz rerwischt sein. Den letzteren Umstand kann man auch an jedem (inzelnen Markstrang konstatieren und er berechtigt infolgedessen zur Ammahme, dass die meisten Zellelemente des Markstroma, die wir auch hier ,, Stromazcllen “ nennen wollen, ihren Ursprung in Marksträngen laben müssen. Sie sind immerhin den Elementen der letzteren morphologisch sehr ähnlich. Es fehlt hier natürlich auch an bindegewebigen 
Elementen nicht; sie sind jedoch nur ganz spärlich. In Marksträngen findet man zuweilen Urei differenziert.

10 Tage alt. (H. 84. Hellbraun, gefleckt, eine Art Hühnerhund. 10. II. 1927.)

Unter dem Keimepithel tritt die Bindegewebslage, als sog. sekundäre Albuginea, deutlich hervor. Die Keimepithelzapfen finden sich hin und wieder. Die Keimstränge sind dick, vom Stroma scharf begrenzt. Das letztere bietet hier ein sehr fibröses Aussehen, so gut wie das gewöhnliche Bindegewebe. Die Stromazellen sind verhältnismässig spärlich, haben in morphologischer Hinsicht mit Elcmenten der Keimepithelzapfen manche Ähnlichkeit. Sie gehen an der oberflächlichon Schicht in die letzteren über und lassen sich in der tieferen Zone von den Markstromazellen gar nicht unterscheiden.

Das Mark scheint auf den ersten Blick in wesentlichen aus Stroma zu bestehen. Die Markstränge finden sich da verhältnismässig wenig, an der Rindengrenze jedoch reichlich. Nach genauer Prüfung konnte man erst feststellen, dass sie in der Tat nicht gering, sondern eher zahlreich vertreten sind. Sie kommen nur nicht auffallend zum Vorschein, weil sie gegen das Stroma nicht ganz scharf abgesetzt sind. Die Markstränge und die Haufen der Stromazellen gehen nämlich ineinander über, indem die Zellelemente von beiden sich morphologisch ganz gleich verhalten. Mit anderen Worten sind die Zellen der Markstränge in Begriff, sich hier und da zerstreut in das Stroma hinzuziehen, um dessen Element zu werden. Bemerkenswert ist es ferner, dass die Markstränge häufig mit gewissen Keimsträngen der Rinde dicht verbunden sind. Es gibt übrigens noch innerhalb des im allgemeinen fibrillären Stromagewebes eine Anzahl von Stromazellen, die mit mehr oder minder länglichen Kernen versehen und dann den gewöhnlichen Bindegewebszellen sehr ähnlich sind.

Immerhin unterliegt es dennoch keinem Zweifel, dass das meiste Zellelement des Stromagewebes hier auf Kosten der Markstränge produziert worden ist.

14 Tage alt. (H. 50. gemischt. 14. III. 1925.)

An der Rinde ist die Aufteilung der Keimstränge deutlicher geworden. Diese letzteren gehen an der oberflächlichen Schicht stellenweise in den Keimepithelzapfen unmittelbar über, indem ihr Element sich immer mehr verkleinert, je mehr es an diesen herannalht, um dort indifferent zu werden. 


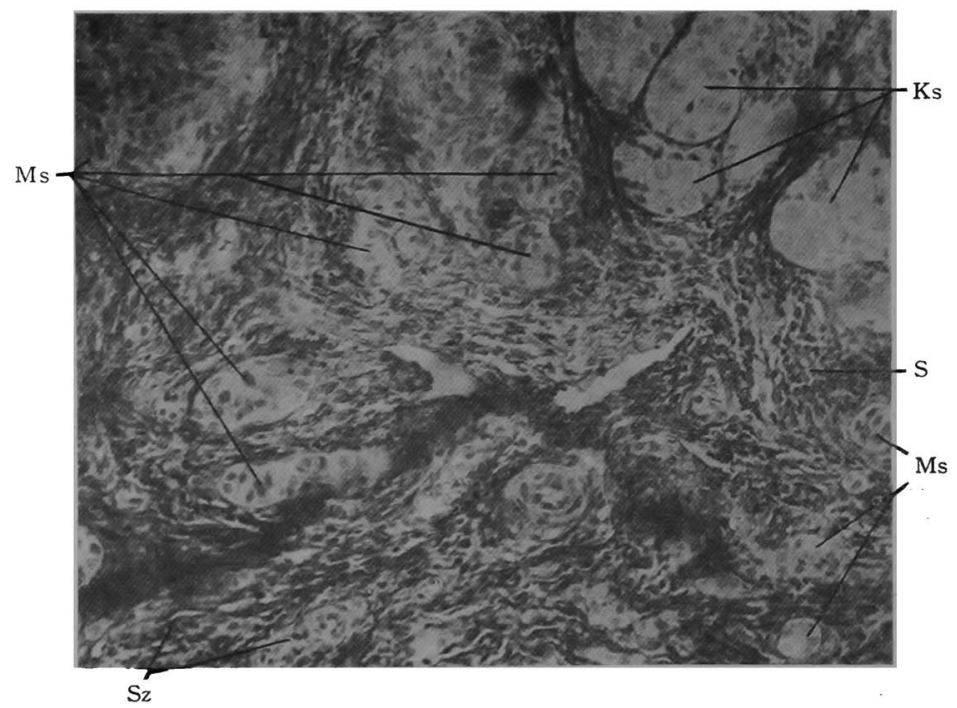

Fig. 2.

14 Tage alt. $190 \times$

Ks Keimstrïnge. Is Markstrïnge. S Stroma. Sz Stromazellen.

Das Stroma erscheint fibrillär und demgrmäss zellenarm. In der Markzone findet sich eine grosse Anzahl von verhältnismässig kleinen Narksträngen und Stromazellen, welch letztere verstreut oder gruppiert vorkommen. In letzterem Falle gehen sic oft in die Markstränge über. Bei diesem Material färbt sich übrigens aus einem ganz unbekannten Grunde der fibrilläre Bestandteil des Stroma durch Hämatoxylin sehr intensiv, sodass die Verteilung der Zellelemente darin ausserordentlich klar ins Auge fällt. Das Plasma der Markstrangzellen ist im allgemeinen hell, während dasjenige der Stromazellen viel dunkler aussieht. Der Unterschied zwischen beiden ist sonach meist sehr leicht zu erkennen, es sind aber auch Zwischenstufen nicht selten.

17 Tage (H. 72. braun, cine Art Spürhund, remischt,

$$
\text { 8. V. 1927.) }
$$

Die zapfenförmige Einstülpung des Keimepithels ist besonders hochgradig nahe am Hilus zu treffen. Die Aufteilung der Keimstränge ist weiter fortgerückt als vorher, die meisten Eizellen sind in Teilung begriffen. Innerhalb des Stroma befinden sich merklich lange Korne in Menge, welche oft sozusagen in Garben gebunden und sogar nicht solten in die Mitte der Keimstränge hineingesteckt zum. Vorschein kommen. 
Vie ein solches Bild zu stande kam, welche Bedeutung os hat, darüber haben wir vorläufig nichts bestimmtes zu sagen.

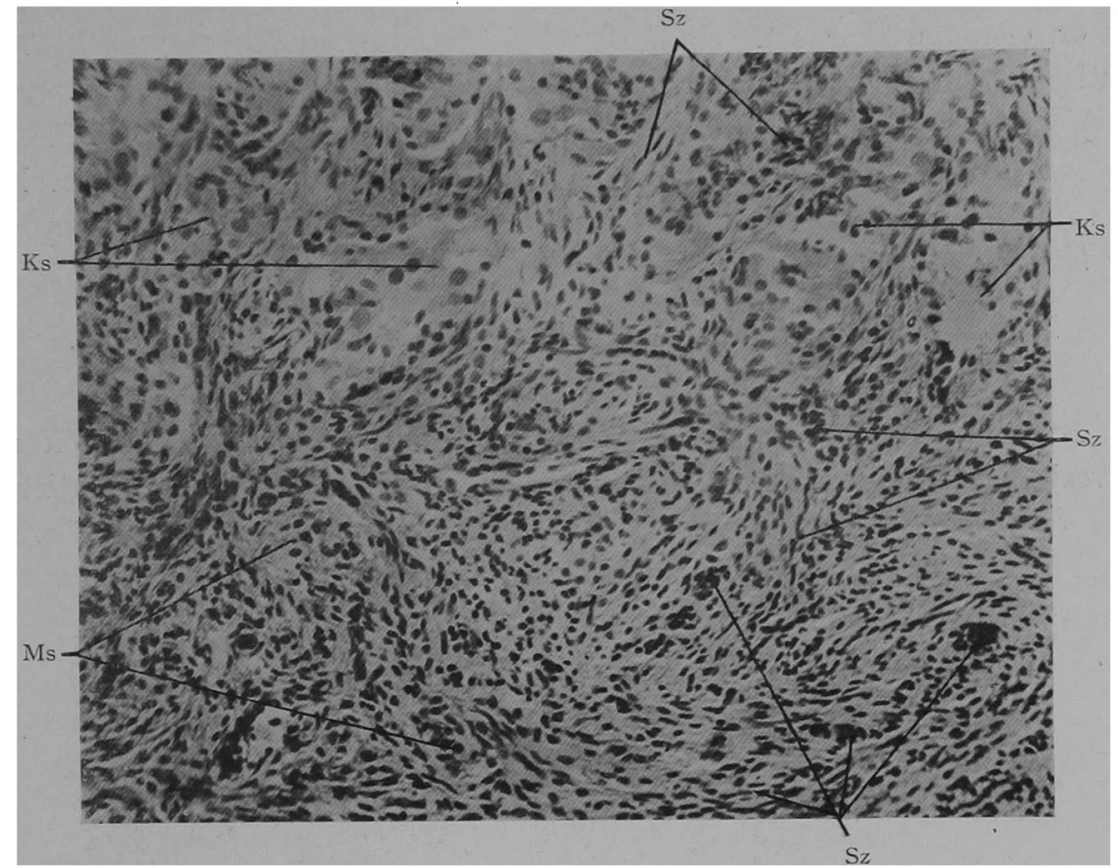

Fig. :?.

17 Tage alt. $190 \times$

Ks Keimstränge. Ms Markstränge. S\% Stromazellen.

Das Mark besteht, ausgenommen die Nachbarschaft les Hilus, aus dem eigentlichen zellreichen Stromagewebe, dessen Zellelement an meisten in Reihen gesammelt vorkommt, welche in verschiedener Richtung durcheinander gehen. Die Markstränge sind in eigentlicher Form nur schr selten, als nicht wohl begrenzte Zellstränge jecloch hin und wieder zu finden. Die Zellen der letzteren können ebenso gleich den gewöhnlichen Markstrangzellen helles Plasma hal)en, sehen jedoch zum grössten Teil lunkel aus, färben sich mit Eosin gut. Derartige Zellformen, welche wir überall im Stroma verstreut oder in kleineren Gruppen treffen, und die gewöhnlichen Stromazellen mit länglichen Kernen sind durch viele Zwischenformon miteinander verbunden.

20 Tage. (H. 73. Teebraun, eine Art Spürhund, gemischt.

$$
\text { 8. V. 1927.) }
$$

Das Element des Keimcpithelzapfens ist gerade im Begriff, sich nach 
dem Stroma zu zerstreuen. Die Rinde verhält sich ganz gleich wie im vorigen. Das Stroma bildet an der Rindenmarkgrenze eine dicke Schicht. Der Markstrang ist meist dümn, zuweilen auch ausgehöhlt, wo er etwas dicker ist. U̇berhaupt ist seine Auslildung nicht sehr deutlich. Im Gegensatz dazu treten die Stromazellen zahllos auf. Ihre morphologischen Verhältnisse erimnern teils an diejenigen der Markstrangzellen, teils aber vielmehr an interstitielle Drüsenzellen; in letzterem Falle mehr oder minder deutliche Hypertrophie und Eosinophilie der Zellen.

21 Tage. (H. 32. Eine Art Hühnerhund, teehraun, gefleckt. 22. I. 1923.)

In Einzelheiten gleich wie im vorigen. Auf den Präparaten mit Meves'-Fixation und Eisenhämatoxylinfärbung konnte man konstatieren, dass die Stromazellen bedeutende Granula-struktur aufweisen, während den Markstrangzellen dieselbe nicht zukommt.

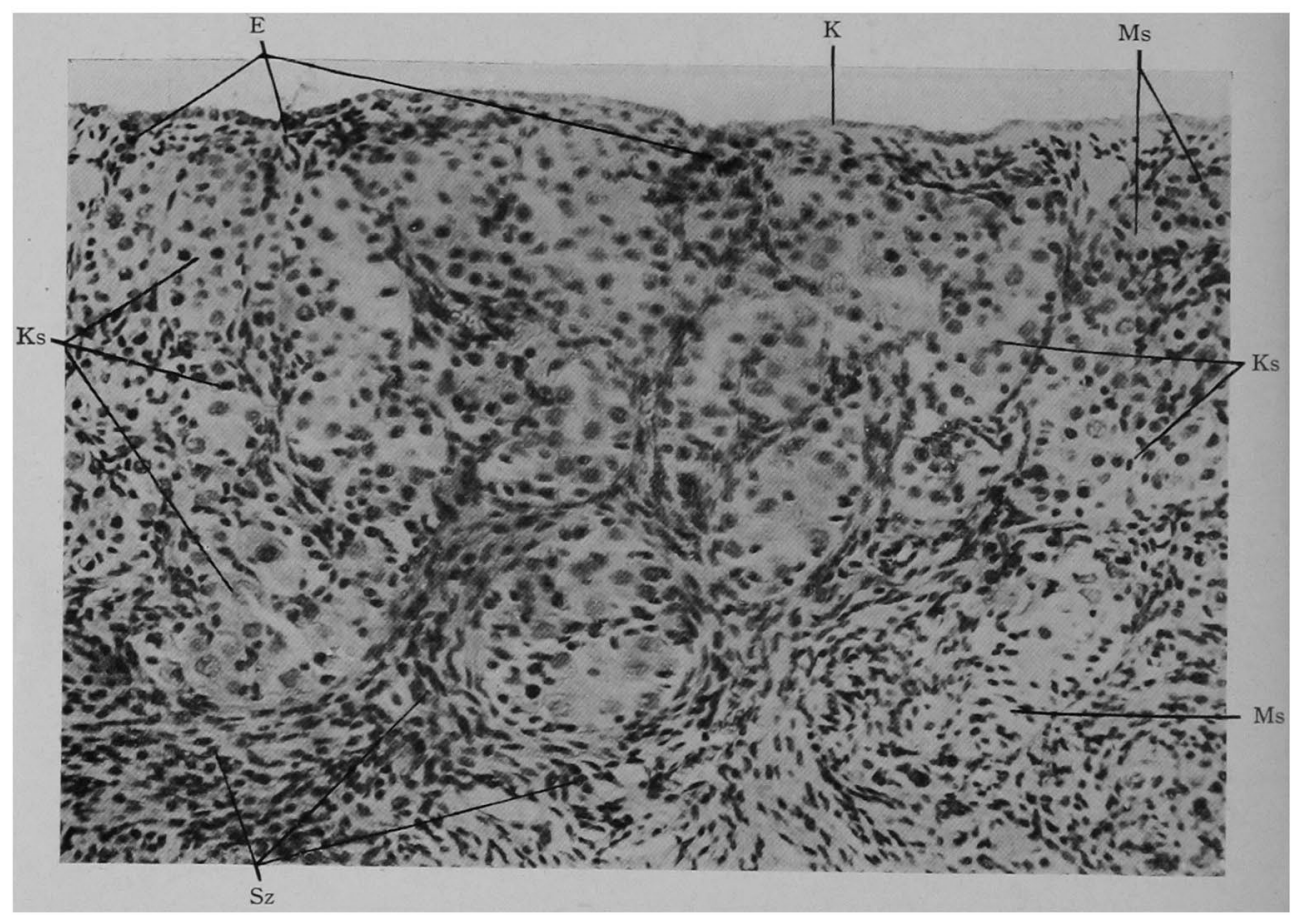

Fig. 4.

23) Tage alt, $190 \times$

E Epithelstränge durch Einstülpung des Keimepithels. Ǩs Keimstränge. $\mathrm{K}$ Keimepithel. Ms Markstränge. S Stromazellen. 
23. Tage. (H. 74. Teebraun, Spürhund, gemischt.

$$
\text { 11. V. 1927.) }
$$

Zapfenförmige Einstülpung des Keimepithels ist stellenweise ersichtlich. Sie kann zuweilen in der subepithelialen Lage des Stroma besondere Haufen bilden. Die Keimstränge sind meist in Eiballen aufgeteilt, worin vielfach Mitosen vor sich gehen. Das Stroma zeichnet sich als Bindegewebe aus, die Stromazellen sind besonders reichlich sowohl an der oberflächlichen als auch der tieferen, dem Mark nahen Schicht.

Das Mark besteht aus sehr zelleureichem Stroma. Der Markstrang ist in eigentlicher Gestalt verhältnismässig gering. Dort sind die Stromazellen zum Teil mehr oder minder deutlich hypertrophisch und eosinophil geworden, indem sie somit von der Umgebung wohl begrenzt sind. Sie bieten, meist in Haufen resp. Nestern gesammelt, das Bild interstitieller Drüsen dar. Es fehlen auch innerhalb des Markstrangs Zellen nicht, die ganz dieselbe Veränderung wie die Stromazellen aufweisen. Dies mag daher kommen, dass beide genetisch naheverwandt sind.

25 Tage. (H. 71. Spürhund, teebraun. 29. IV'. 1927.)

Die zapfenförmige Einstülpung des Keimepithels tritt ziemlich deutlich hervor. Primäre Follikel sind teilweise, besonders in der tieferen Lage im Begriff, sich von den Eiballen abzutrennen. Die Eizellen sind überhaupt sehr hypertrophisch geworden.

Im Mark befinden sich die eigentlichen Markstränge nur selten; es treten dagegen die Stromazellen ganz bedeutend hervor. Sie sind da mehr oder minder hypertrophisch und mit Eosin gut färbbar, sodass sie sich ganz gut abgrenzen lassen. Sie bilden sogar meist gewisse Zellhaufen resp. -nester und geben demnach mehr den Anschein einer interstitiellen Drüse. Ganz dieselbe Veränderung kann auch das Element eines Markstranges zeigen. Es lässt sich dann von den Ersteren in histologischer Beziehung gar nicht unterscheiden.

27. Tage. (H. 75. Teebraun, gefleckt, Spürhund, gemischt. 29. IV. 1927.)

Zapfenförmige Einstülpungen des Keimepithels finden sich stellenweise. Die Keimepithelzellen werden oft hypertrophisch und schliessen eosinophilen Inhalt in sich ein. Die Keimstränge stellen sich in Form von Eiballen dar. Es gibt noch keine primären Follikel, ebensowenig ihre Verbindung mit dem Keimepithelzapfen. 


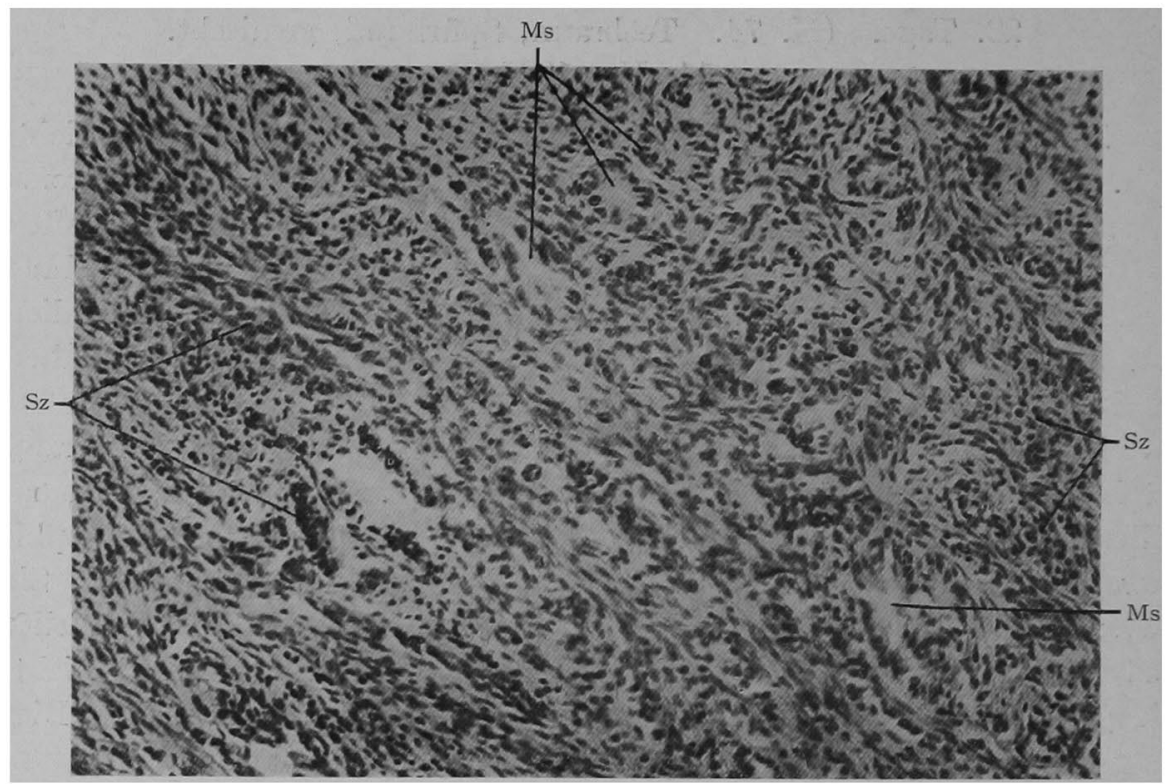

Fig. 5.

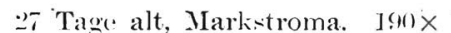

Is Markstränge. II\% Stromazellen.

In Mark findet man gleich sowohl die Markstränge als auch Stromazellen gut ausgeprägt. Da die letzteren gewissermassen hypertrophisch und mehr oder minder in Haufen gesammolt sind, erwecken sie deutlich den Anschein einer eigentlichen interstitiellen Drüse. Rete ovarii ist teilweise ersichtlich.

\section{Tage. (H. 43. gemischt. 7. III. 1925.)}

Sehr reich an Keimepithelzapfen, welche zusammen eine besondere subcpitheliale Zone bilden können. Sic sind meist solid, scheinen teilweise wie verästolt. Gegen das Stromagewebe pflegen sie sich scharf abzugrenzen, aber es kam der Fall sein, dass sie sich auflösen, um in Stromazelln überzugehen. Sie kömnen ferner zuweilen Lumen haben und dürften dann wohl als die erste Anlage dor der Hündin eigentümlichen Keimschläuche betrachtet werden.

Die Eiballen sind hier fast zum grössten Teil in primäre Follikel aufgeteilt. An der oberflächlichen Zone finden sie sich sonst mehr oder minder in Gruppen, wo sie nicht ganz getrennt sind. Sie sind ja zum kleineren Teil schon auf dem Wege sich weiter zu entwickeln. Besonders ist hier noch als bemerkenswert hervorzuheben, lass das Rindenstroma Enden 
der Markstränge tief in sich hereindringen lässt. Man trifft an der ticferen Rindenzone am meisten dickero von ihnen, an der mittleren dagegen feinere,' welch letztere an dio neugetrennten primären Eifollikcl oder deren Gruppe dicht angeschmiegt ihren Platz finden und sogar noch weiter in die oberflächliche Rindenzone fortschr'(iten können.

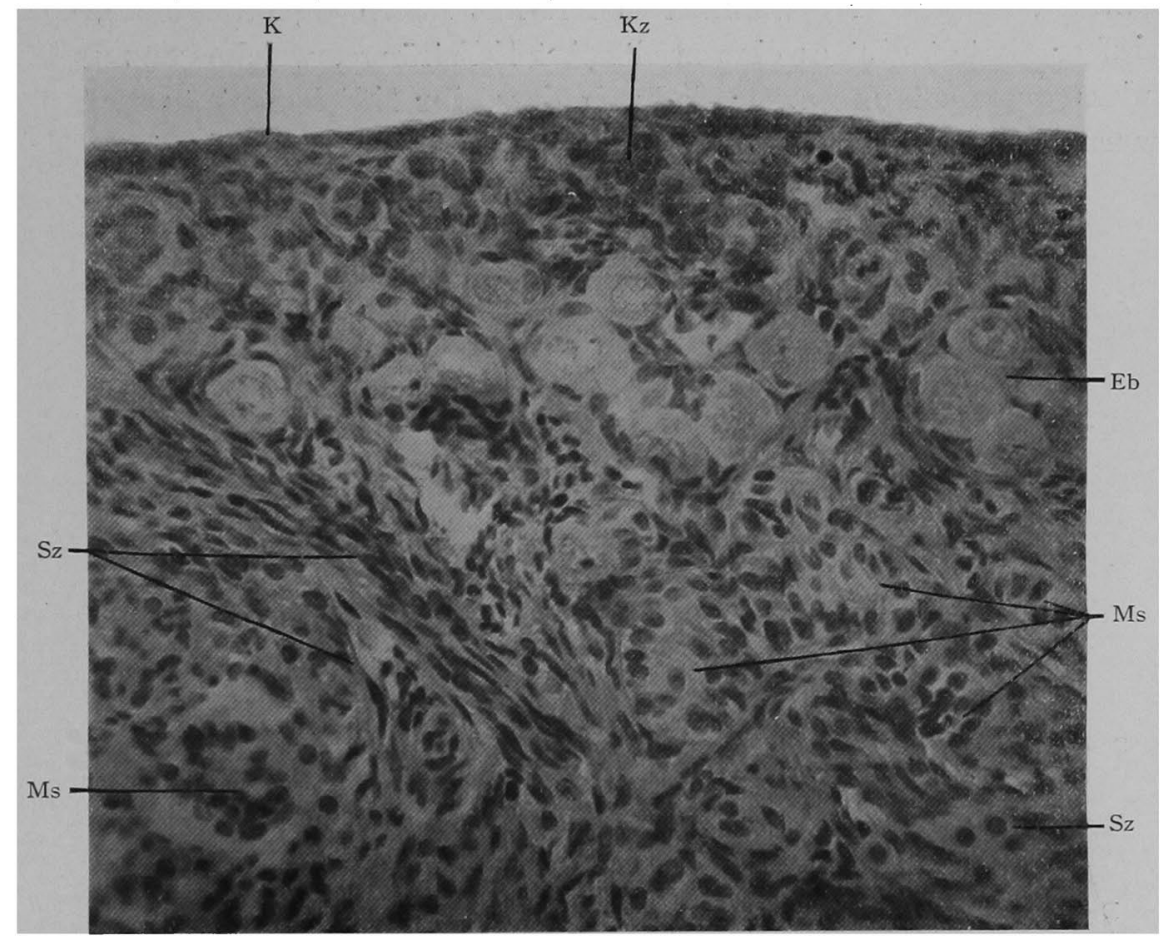

Fig. (6.

30 Tage alt. $350 \times$

Eb Eiballen. K Kcimepithel. Kz Keimepithelzapfen. IIs Markstränge. S\% stromazellen.

Der Zellbestanılteil der betreffenden Stränge ist wie schon erwähnt durch seine Helligkeit, besondere cylindrische Form und Anordnung charakterisiert und lässt sich somit ganz gut unterscheiden. Eine Zerstreuung ins Rindenstroma ist nicht zu sehen. Es gibt in der Tiefe der Rinde oder in deren Nachbarschaft eine besondere Form von ziemlich dicken Marksträngen, in wolchen Eizellen auftreten, und die sich also als ziemlich entwickelto Eifollikel erweisen.

Im Marke fällt eine grosse Anzahl von Marksträngen ins Auge. Die sonstigen Zellelemente dort sind hauptsächlich den Stromazellen 
gehörig, deren Herstammung nach obiger Schilderung ausschliesslich von Marksträngen abgeleitet und deren Natur somit ebenfalls epithelial betrachtet werden mag. Die bindegewebigen Elemente sind dagegen verhältnismässig gering, ihre Unterscheidung von jenen ist meist klar.

Die Markstränge bestehen hier augenscheinlich in zwei Arten. Nämlich, ausser der gewöhnlichen Art mit Zellen eigentümlicher, cylindrischer Gestalt gibt es eine zweite Art Zellstränge, welche ganz und gar anders aussehen und zwar dadurch dass, ihr Zellelement äusserst plasmaarm ist. Da der Kern des letzteren in der Regel sich stark färbt,

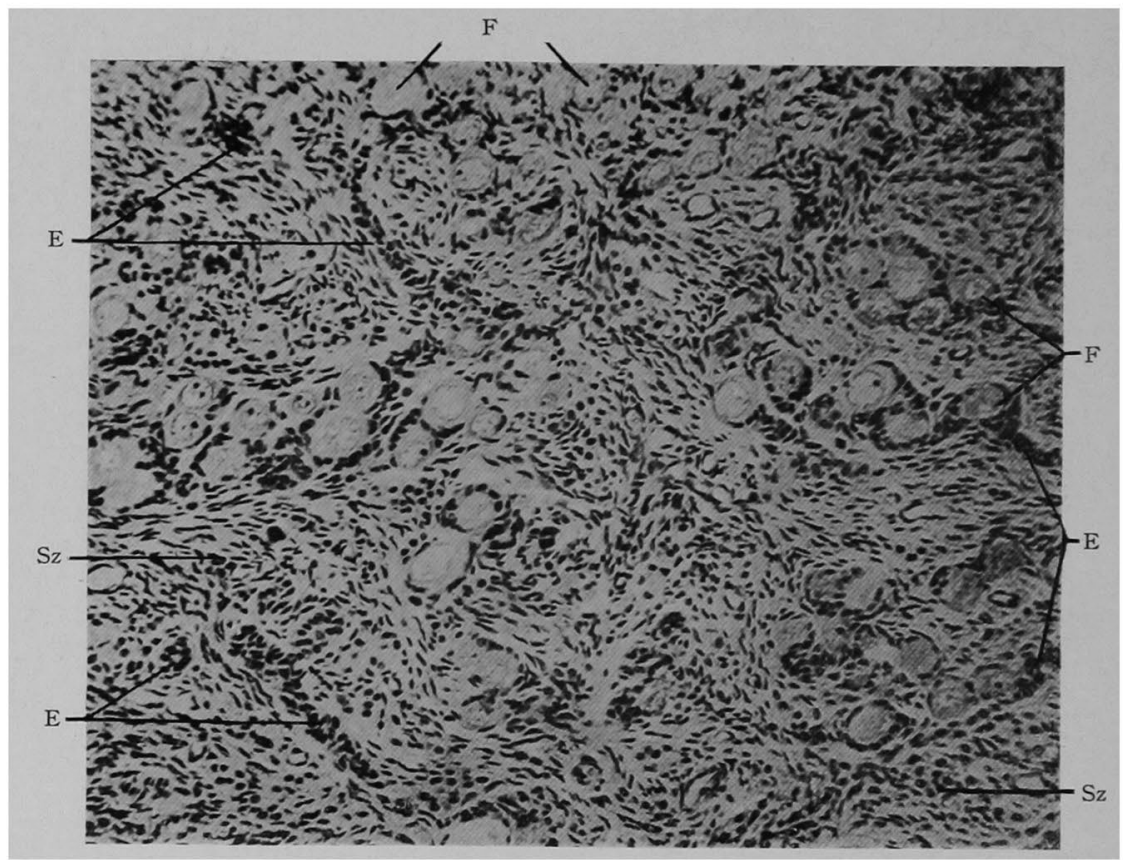

Fig. 7 .

4) Tage alt. $190 \times$

E Epithelstränge. F Primärfollikel. $s_{z}$ stromazellen.

erscheinen sie als blosse Kernanhäufung in Reihen, wenn man sie in einer schwachen Vergrösserung sieht. Solche Zellstränge kommen an einer bestimmten Stelle des Markes äusserst zahlreich zum Vorschein. Nach genauer Untersuchung komnte man jedoch konstatieren, dass sie mit den Haufen resp. Nestern der Stromazellen, welche genetisch vom Markstrang abgeleitet werden sollten und weit mehr plasmareich und mit Eosin färbbar sind, durch allerhand Zwischenformen vorbunden sind. Demzufolge unterliegt es keinem Zweifel mehr, dass die genannten 
Zellstränge genetisch vom Markstrang ersterer Art abgeleitet worden oder wenigstens diesem nahe verwandt sind, wenn sie auch dem Aussehen nach ganz verschieden auftreten.

45 Tage. (H. 59. Eine Art Hühnerhund, schwarz.

30. IV. 1925.)

Keimepithelzapfen in geringer Menge. An der Rinde sind die primären Follikel meist gut differenziert. Die Stromazellen treten dort ja auch zahlreich mehr oder weniger deutlich gruppiert auf, haften häufig den Eifollikeln an, oder können sich in Stränge aneinander reihen. Die diesbezüglichen Zellen sind am meisten plasmaarm, erscheinen somit in der Hauptmasse als Kernhaufen, wemn sie sich ansammeln. An bestimmten Stellen, unter anderem der oberflächlichen subepithelialen Zone, werden sie jedoch zuweilen hypertrophisch, kömmen sogar hochgradige Schaumstruktur aufweisen. Kurz, nach unserer Beobachtung nehmen die Rindenstromazellen hier nur zum geringeren Teil im Keimepithelzapfen, zum grössten Teil aber im Markstrang ihren Ursprung demn sie mögen unmittelbar nach diesem verfolgt werden.

Das Mark verhält sich ganz gleich wie im vorigen.

60 Tage. (H. 41. Hühnerhund-gemischt, teebraun-gefleckt.

$$
\text { 3. III, 1925.) }
$$

Die Keimepithelzapfen finden sich stellenweise sehr zahlreich, bald solid, bald ausgehöhlt. Sie bilden dann zusammen eine besondere subepitheliale kontinuierliche Schicht. Ihre Abgrenzung erscheint zum Teil nicht scharf, wo ihr Element sich von dem des Stroma gar nicht unterscheiden lässt. Die primären Follikel sind lockerer verteilt als vorher, das Stroma in demselben Masse reichlich. In letzterem werden Mengen von kleineren und grösseren Zellsträngen gefunden. Sie stehen ja oft an der oberflächlichen Schicht einerseits mit den Keimepithelzapfen in Verbindung, gehen an der tieferen andererseits unmittelbar in die Markstränge über, indem sie teilweise dicht den primären Follikeln anhaften.

Die Markstränge treten sehr reichlich, jedoch in kleinerer Dicke auf. Ihr Element ist gewöhnlich hell, es kann jedoch daneben solche geben, die sich mehr oder weniger verdicken und Eosinfarbe annehmen. Auch die wohl differenzierten Stromazellen erscheinen hier am Marke mehr oder minder deutlich in Säulen resp. Strängen gruppiert. Es zeigt sich demnach im allgemeinen das Bild einer sehr gut entwickelten 
interstitiellen Drüsc. Das gewöhnliche Bindegewebe scheint hier im Vergleiche mit der Rinde nur gering zu sein.

60 Tage. (H. 70. Eine Art Spürhund, hellbraun.

10. II. 1927.)

Es gibt eine grosse Anzahl von Keimepithelsträngen, welche zusammen eine ziemlich dick» subepitholiale Schicht ausmachen. Sie sind

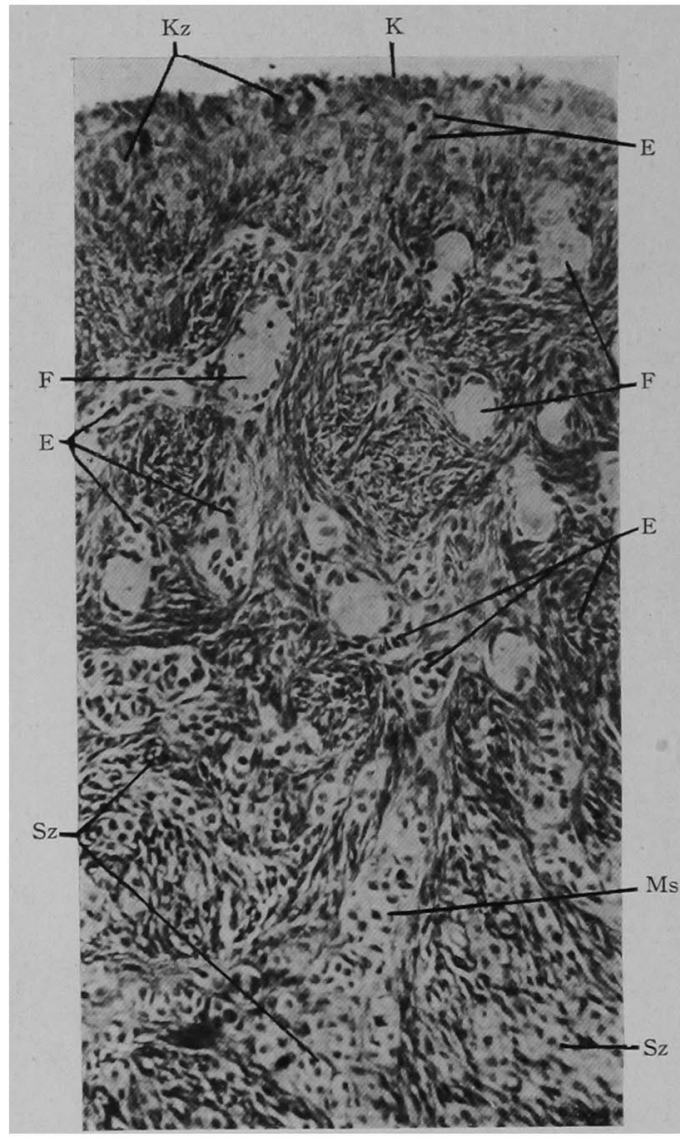

Fig. 8.

60 Tage alt. $190 \times$

E Epithelstränge. F Eifollikel. K Keimcpithel.

K\% Koimepithelzapfen. Ms Markstränge. S\% stromazellen (interstitielle Zellen). meist mit Lumen versehen, können Eizellen auftreten lassen, und die tiefsten von ihnen gehr'n sogar zuweilen über diese Schicht hinaus in die Stromazellen der Rinde über. Dies Präparat zcichnet sich übrigens durch Zellonreichtum in Rindenstroma und die sehr starke Ausprägung der interstitiellen Drüsc aus, indem dir Markstromazcllen sich in allgemeinen deutlich verdicken und sich mit Eosin intensiv färben. Sonst ganz gleich dem vorigen.

Ein halbes Jahr. (H. 62. Teebraun, gemischt.

$$
\text { 3. T. 1925.) }
$$

Die Keimepithelzapfen sind deutlich ausgeprägt und lassen in der subepithelialen Schicht äusserst zahlreiche Zallstränge sich entfalten. Durch die Zellen-rerdickung und Aushöhlung der letzteren bilden sic zum Teil solche, deren man sich ja gerade bei den späteren Keimschläuchen erinnert ; sic dringen zum anderen Teil tief in die Rinde hincin, verzweigen sich in immer feinere Zellstränge, bis sie sich endlich, wie es scheint, im Stroma zerstreuen. 
An der Rinde ist verhältnismässsig Mangel an Follikelı. Die tiefer gelegenen zeigen .Neigung sich mehr oder minder zu entwickeln. Im bindegewebigen Stroma befinden sich ausser Zellsträngen, die vom Keimepithel stammen, reichliche Markstränge. Da die letzteren sich an den besonderen Merkmalen ihrer Zellen wie oben erwähnt kenntlich machen,

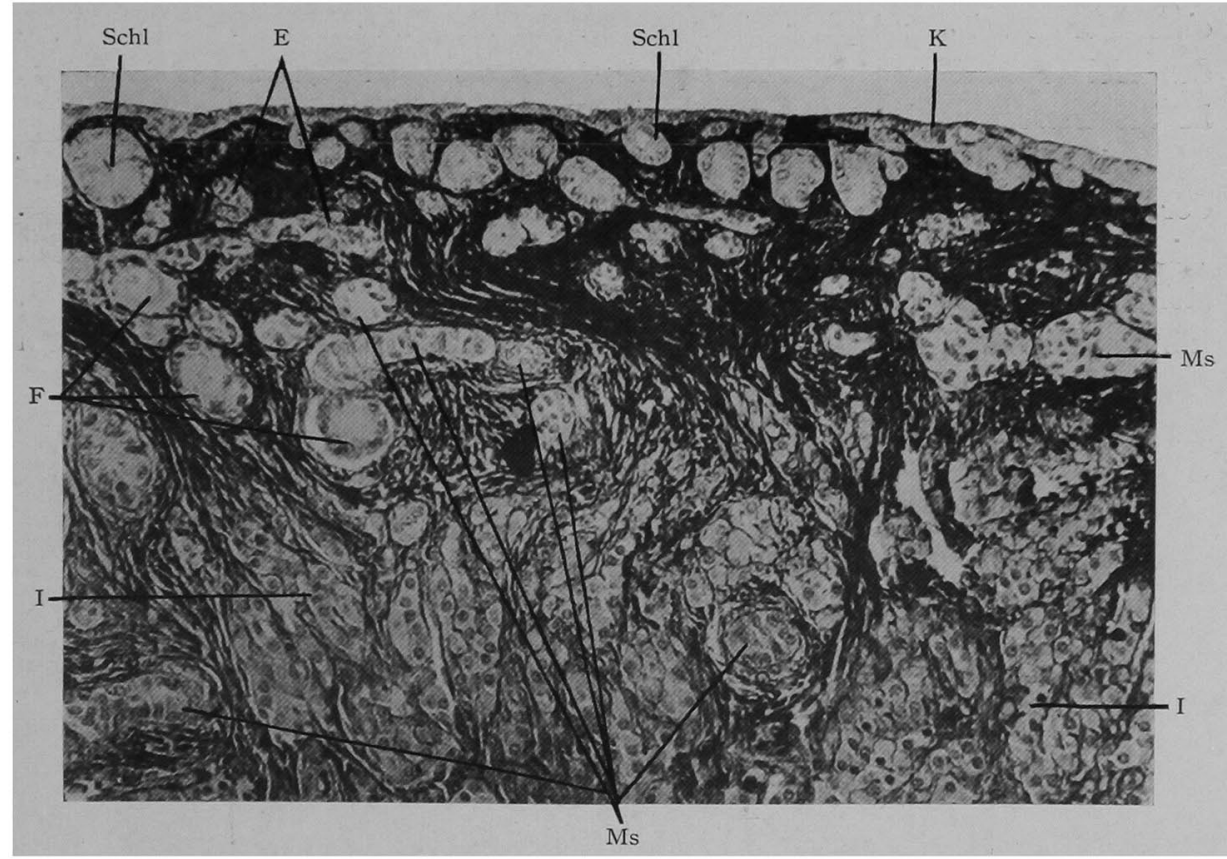

Fig. !).

Ca. 6 Monate alt. $190 \times$

E Epithelstränge. F Eifollikel. I Interstitielle Drüse. K Keimepithel. Ms Markstränge. Schl Keimschlauch.

lassen sie sich von den ersteren sehr leicht unterscheiden. Im übrigen färbt sich das Bindegewebe des Rindenstroma sehr intensiv.

Das Mark übertrifft an Masse die Rinde stark, was in einem noch weit früheren Alter zutage zu treten geneigt ist. Hier erkennt man das Bild hochgradiger interstitieller Drüsen. Es erfolgt daraus, dass die betreffenden Zellen hypertrophisch, mit Eosin stark gefärbt und vom Bindegewebe somit scharf abgesetzt werden. Sie erstrecken sich teils auch inmerhalb des Rindenstroma. Die Markstränge treten reichlich meist als dünne Zellstränge auf, die sich oft verzweigen. Ihr Zellelement behält eine eigentümliche Helligkeit bei. An einem Teil des Markes kann es ziemlich riel Bindegewebe geben. 
Ca. Ein Jahr alt. (H. 61. gemischt. 9. V. 1925.)

Die Oberffäche des Ovariums ist sehr uneben, demgemäss ist das Keimepithel eingezogen und hervorgesprungen. Die Keimschläuche scheinen in eine typische Entwickelung gelangt, indem sie alle eine besondere subepitheliale Lage einnehmen. Dort gibt es daneben noch eine Menge solider Epithelstränge, welche sich zweifelsohne von Seiten des Keimepithels durch Einstülpung hervorbringen lassen und teils noch in die Tiefe eindringen, um Stromazellen abzugeben.

Die Follikel sind meist auf dem Wege heranzuwachsen. Es war der erste Fall, bei dem wir den Folliculus vesiculosus gefunden haben. Die Markstränge, die da Plat\% nehmen, entwickeln sich sehr stark und stellen sich als beträchtlich dicke Zellstränge dar. Sie sind meist solid, können jedoch teils ausgehöhlt sein. Beim lotzteren Falle sind sie einem

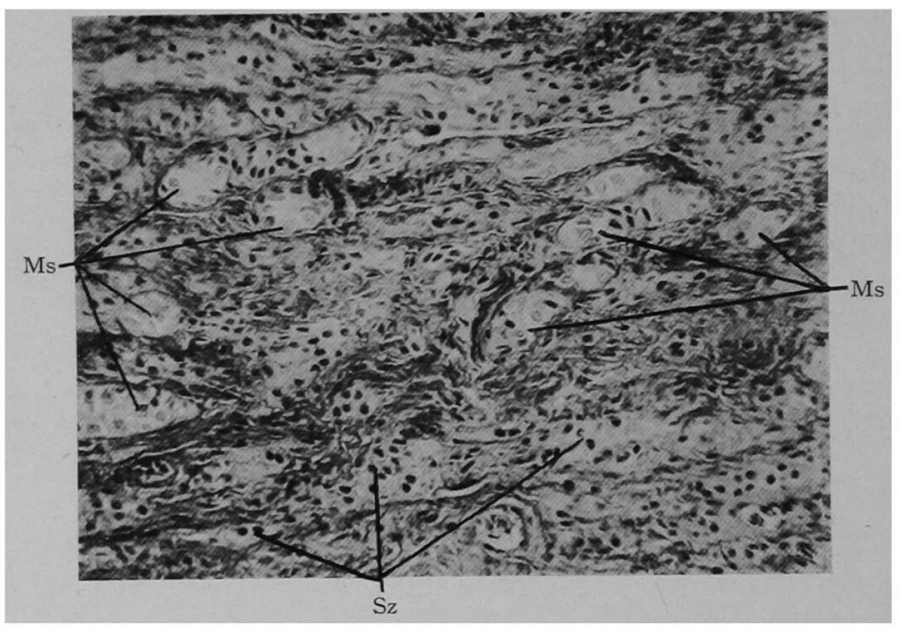

Fig. 10.

Ca. 6 Monate. $190 \times$

IIs Markstränge. š Stromazellen.

vesiculösen Follikel fast zum V'erwechseln ähnlich, falls man ein Ei da findet. Als Unterscheidungsmerkmal ist wohl hervorzuheben, dass die genannten Gebilde in der Mehrzahl der Fälle Eier entbehren, und dass sie sich etwas anders gestalten d. i. nicht kugelrund wie gewöhnlich, sondern mehr oder weniger langgezogen oder sogar ganz derart unregelmässig, wie es auch beim Markstrang sein könnte, und endlich dass ihr epitheliales Element dieselbe Eigentümlichkeit besitzt wie das der Markstränge. Das Rindenstroma ist in der Hauptmasse bindegewebig d. h. fibrillär. Die 
Stromazellen finden sich dort nur an der subepithelialen Schicht und der Wand der grossen (vesiculösen) Follikel, in ziemlich grosser Menge gruppiert. Sonst noch sind. kleine Markstränge zerstreut zu finden.

Das Mark 'besteht auch fast nur aus Bindegewebe. Die Stromazellen (interstitielle Drüse) sind in sehr geringer Menge vorhanden. Die Markstränge sind am Mark nicht mehr zu finden, sondern immer an der Rindengrenze, wo sie sich sehr verdicken wie oben erwähnt.

Anderthalb Jahre. (H. 17. gemischt, hellbraun, weiss gefleckt.

6. XII. 1923.)

Das Keimepithel und die Keimschläuche verhalten sich hier ganz gleich wie bei der einjährigen. Die Follikelzahl ist verhältnismässig gering, dagegen das Stroma sehr reichlich. Das letztere ist zellreich und schliesst zahlreiche solide oder ausgehöhlte Zellstränge in sich. Dass sie zum grössten Teil vom Markstrang stammen, lässt sich aus der histologischen Beschaffenheit der Zelle leicht erkennen. Zum kleineren Teil aber handelt es sich sicherlich um solche, die zum Keimepithel Beziehung haben. Die Eifollikel sind besonders in der tieferen Schicht in grosses Wachstum geraten. Mehreiige Follikel sind auch da.

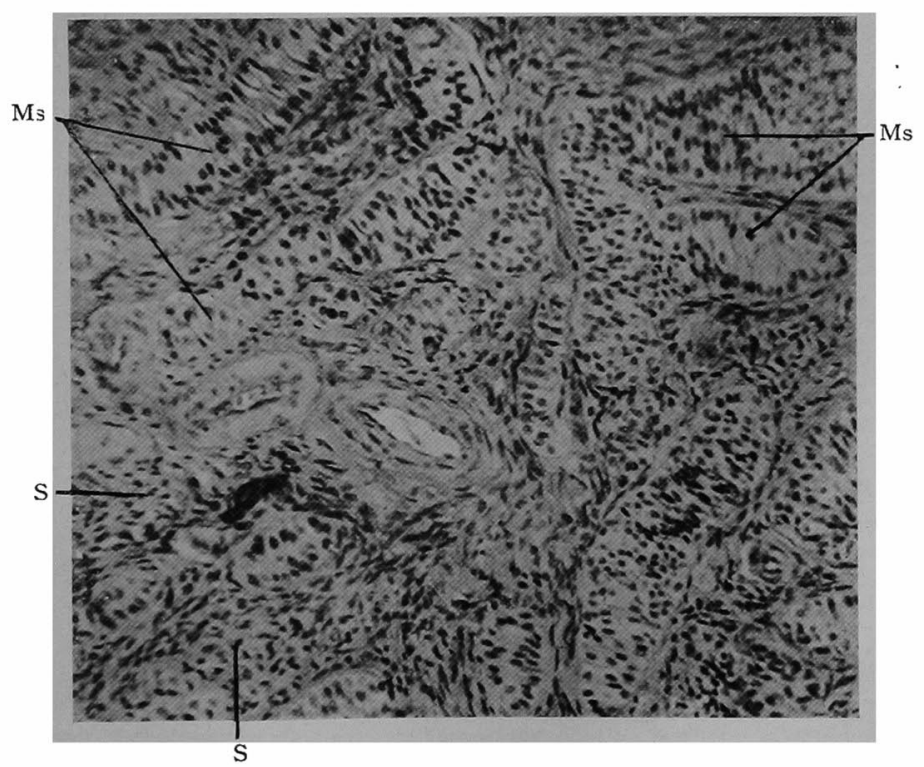

Fig. 11.

Anderthalb Jahre. $190 \times$

MIs Markstränge. S Stromagewebe. 
An dem Mark gedeihen die Markstränge ausserordentlich stark. Dort sind sie nicht nur zahlreicher, sondern teilweise beträchtlich dicker. Sie können ganz solid oder ausgehöhlt sein. Letztere Form dürfte nicht selten mit den Rückgangsformen des Follikels verwechselt werden. Diesen letzter'n begegnet man sehr oft; nichtsdestoweniger trifft man gar keine typische Atresie des Follikels, die eine Terdickung der imneren Thecaschicht herbeiführen würde. Fast keine Andeutung der interstitiellen Drüsen, dagegen reichliche Stromazellen im Mark.

Erwachsene Hündin. (H. 37. gemischt. 20. II. 1925.)

Das Terhalten des Krimepithels und der Keimschläuche ist gleich

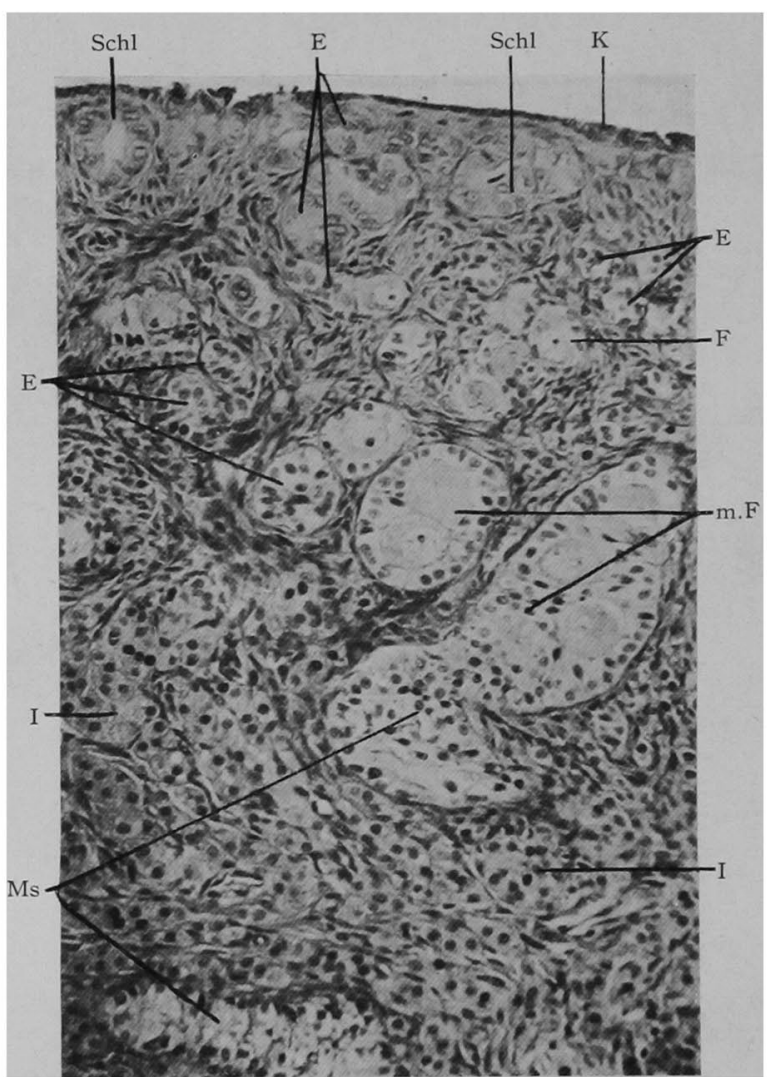

Fig. 12.

Erwachsene Hündin. $190 \times$

E Epithelstränge. F Eifollikel. I Interstiticlle I)rïsc (Stromazellen). K Keimepithel. m.F mehreiige Follikel. IIs Markstränge. Schl Keimschlauch. wie in vorigen. Primäre resp. jüngere Follikel sind wie gewöhulich an der oberflächlicheren, grö̈sscre' aber meist noch solide Follikel an der tieferen Schicht der Rinde ersichtlich. An der tieferen Riudenzone bemerkt man besonder: reichlich Markstränge sowic Zellnester, welch letztere die Gestalt interstitieller Drüsen erkennen lassen. Mclneeige Follikel trifft man nur in ziemlich grossen Wachstumsformen. Sie sind nicht kugelrund sondern mehr in die Länge gr(\%ocren. Es kamn sogar den Anschein haben, als ob sic dadurch zustande kämen, dass irgend ein langer Epithelstrang gerade da sich kuglig auftreibt, wo das $\mathrm{Ei}$ herrorgewachsen ist. 
An solchen Follikeln haben die Follikolzellen merkwürdigerweise mit den Markstrangszellen in mancher Hinsicht (Zellform, Anordnung usw.) viele Ähnlichkeit. Das Rindenstroma ist im übrigen zellenreich.

Am Mark findet man zahlreiche Markstränge, die sich in eigentümlicher Weise überall hin erstrecken. Ferner kommen die interstiticllen Drüsen in recht reichlicher Menge zum Vorschein. Da ihr Element sehr hypertrophisch und durch Eosin gut färbbar ist, lässt es sich vom Markstrangelement meist scharf unterscheiden. Es gibt aber zuweilen bestimmte Stellen, wo die genannte Abgrenzung zwischen beiden sich ganz verwischt, und zwar dadurch, dass das Markstrangelement ebenfalls Eosinfarbe annimmt, wodurch dann beide ineinander übergehen. Die interstitiellen Drüsen sind teilweise in Rückgang geraten, wohl indem sie sich allmählich narbig umwandeln.

\section{Zusammenfassung.}

Wenn man in Bezug auf die Stromabildung des Fierstockes die obigen Ergebnisse, welche wir an Hündimnen verschiedenen Alter's von 3 Tagen an bis zur Erwachsenen bekommen haben, übersichtlich betrachtet, liegt es zutage, dass das Stroma auch hier nicht ganz einfach aus Bindegewebe besteht. Es ist ja vielmehr aus diesem und einer reichlichen Zellmenge zusammengesetzt. Dass die letztere von keiner bindegewebigen Natur ist, lässt sich meist leicht erkennen, wenn man beides, insbesondere auf Zell- resp. Kerngrösse, -form und Plasmareichtum hin vergleicht. Solche Unterscheidungsmerkmale haben democh nur einen bedingten Wert, könnten somit im Einzehnen dazu gar nicht dienen, streng zu entscheiden. Es würde sich dam beides gar nicht voneinander unterscheiden. Unsere obige Unterscheidung von beiden möchten wir trotzdem für sehr wichtig und angemessen halten, und zwar hauptsächlich unter dem genetischen Gesichtspunkte. Die betreffenden Zellen, welche wir hier oben im allgemeinen , , Stromazellen “" genannt haben, haben nämlich in ihrem genetischen Verhältnis am innigsten Beziehung zu Marksträngen, was wir schon im voraus annahmen. Zuerst bei der jüngsten (3 Tage alten) der Hündinnen, die uns zur Verfügung stand, besteht das Eierstockmark fast ausschliesslich aus Marksträngen sowie deren Element. Mit der Entwickelung der Jungen wandelt sich diese Bauart ziemlich rasch um, indem die Markstränge allmählich ab-, die Stromazellen dagegen zunehmen. Der Grund solcher Veränderung besteht darin, dass die Markstränge ihr Element aus dem epithelialen Verband loslassen und dadurch die Stromazellen immer 
mehr neu erschaffen, wie man bei fast allen wachsenden Tieren bis zu Halbjährigen mehr oder weniger deutlich konstatieren kann. Die Mengenverhältnisse der Markstränge und Stromazellen sind jedoch übrigens gar nicht etwa für die Altersbestimmung eines Jungen massgebend.

Als zweite Quelle der Stromazellen kommt die zapfenförmige Eivstülpung des Keimepithels in Frage. Abgesehen davon, dass die Keimstränge sich bekannterweise auf Kosten des Keimepithels ausbilden, was sich bei der Hündin ebenso wie bei vielen anderen Tieren schon sehr früh zur Zeit intrauterinen Lebens mit der Bildung sog. primärer Albuginea vollzogen haben sollte, müssen wir uns zunächst fragen, welche Bedeutung die genannte Einstülpung des Keimepithels habe, welche sich in der ausseruterinen Entwickelung noch weiter fortsetzt. Soweit es sich um die späteren Stadien handelt, wo die Zapfen resp. Stränge meist hohl erscheinen oder wenigstens dazu geneigt scheinen, könnte man sie wohl als Anlage der hier ganz eigentümlichen Keimschläuche erklären. Was aber die Bedeutung der soliden Epithelzapfen respective -stränge anlangt, die in noch früheren Stadien d. h. vom Neugeborenen an bis zum fast Erwachsenen zum Vorschein kommen, so bedarf sie wohl einer ganz anderweitigen Deutung. Da man an ihnen nicht ganz selten Eier finden kann, dürften sie begreiflicherweise wenn auch zum geringeren Teil an nachträglicher Follikelbildung beteiligt sein, wovon wir dennoch nicht mit Sicherheit $\mathrm{zu}$ sprechen im Stande sind. Es fällt uns dagegen in die Augen, dass die betreffenden Zellstränge stellenweise unmittelbar in die Stromazellen der Rinde übergehen, indem sie sich allmählich wenig scharf abgrenzen und diese von sich losgeben. Diese Sachlage führt uns ungezwungen zu der Annahme, die Bedeutung der genannten Gebilde bestehe im wesentlichen eher darin, dass sie beständig ihr Element nach dem Stroma abgeben, oder was dasselbe ist, auf ihre Kosten soviel Stromazellen erschaffen, bis sie dadurch völlig erschöpft sind, ein Umstand, den etwa Coert, Allen, Whitehead u. a. in einer früheren, embryonalen Zeit angetroffen hätten. Dem Gesagten zufolge braucht man nicht mehr zu bezweifeln, dass die Stromazellen des Eierstockes beim Hund einerseits dem Markstrang, anderseits dem Keimepithel ihren Ursprung verdanken. Sie haben jedenfalls immer epitheliale Natur, ganz gleichgültig, woher es kommt, denn dor Markstrang muss auch seinerseits rückläufig betrachtet, ausschliesslich in dem Kölomepithel seinen Ursprung suchen, welches sich von Bindegewebe ganz unterscheiden lässt.

Die Stromazellen sind in der Regel mit grösseren ovalen oder länglichen Kernen versehen, wolche sich von denjenigen der gleichfalls da 
auftretenden Bindegewebszellen in Grösse, Form und Gestalt meist nicht schwer unterscheiden lassen. Die Ersteren werden unter Umständen hypertrophisch plasmareich, ihre Kerne meist kreisrund, und heben sich dann vou der Umgebung, an der sie sonst ohne deutliche Grenze gelegen sind, ganz scharf ab. Sie sind nichts anderes als die interstitiellen Zellen. An ihnen kömnen wir auf den Eisenhämatoxylin-Präparaten eine Menge färbbarer Körner und Sekrettropfen finden. Sie bieten demnach offenbar sozusagen eine drüsige Struktur dar, und es wäre deshalb recht begreiflich $\mathrm{zu}$ schliessen, dass damit gerade eine tätige Form der Stromazellen getroffen ist. Es folgt daher selbstverständlich, dass der verschiedene Erscheinungsgrad der interstitiellen Drüsen immer durch ihre Tätigkeit bedingt ist.

Da bei der Hündin die interstitiellen Drüsen, soweit uns bekannt, nur in einem Alter von 60 Tagen bis zu einem halben Jahr gefunden werden, sollte man wohl in dieser Zeit zum ersten Mal ihre Tätigkeit finden. Bei der fast erwachsenen sowie schon ganz erwachsenen Hündin kommen sie bald vor, bald nicht, was darauf hinweist, ihre Tätigkeit ginge nicht beständig, sondern wohl an irgendwelche physiologischen Zustände gebunden nur zeitweise vonstatten. Wenn ihre Funktion zu Ende ist, geraten die Drüsen höchstwahrscheinlich im Grossen und Ganzen in Rückbildung bis zum völligen Schwund. Man würde dann wohl denjenigen Umstand vor sich haben, bei dem das Eierstockstroma in der Hauptmasse bindegewebig, an Zellelementen dagegen überhaupt sehr arm ist. Da die Theca-interna-zellen hier, wie bekannt, nur wenig scharf ausgeprägt sind und noch dazu die Follikelatresie in bekannter Weise durchaus nicht zustande kommt, hat sie mit der Abstammung der Stromazellen gar nichts zu tun.

Nach der obigen Schilderung unterliegt es keinem Zweifel mehr, dass der Markstrang den Stromazellen den Ursprung gibt. Er findet sich jedenfalls in verschiedenen Formen und scheint im Stande zu sein, jederzeit wo notwendig Stromazellen zu schaffen. Seine Rolle ist aber, wie wir sehen, damit gar nicht fertig. Er hat nämlich ein ganz enormes Wachstum, so bald das Tier fast erwachsen ist, und wandelt sich wohl in grössere Eifollikel um, und zwar dadurch, dass aus seinem Element eiu oder mehrere Eier in gut entwickelter Form entstehen, während alles übrige die Follikelzellen bildet. Die mehreiigen Follikel, deren Auftreten bei der Hündin ganz eigentümlich erscheint, werden wohl alle in derartiger Weise hervorgebracht. Es gibt ferner dabei sehr viel Markstranggebilde, die mit den gewöhnlichen Follikeln sehr viel Ähnlichkeit haben, ausser dass sie der Eier entbehren. Man weiss nicht, was sie 
zu bedeuten haben. Sie scheinen übrigens fast ganz in Rückgang zu verfallen. In Bezug auf die Beteiligung der Stromazellen an der Bildung des Follikelepithels sei auf die Abhandlug Okamoto's verwiesen.

\section{Schluss.}

1. Das Stromagewebe des Eierstocks besteht aus verhältnismässig geringer Menge gewöhnlichen Bindegewebes und reichlicher Zellmenge, welch letztere hier in allgemeinen ,, Stromazellen " genannt werden.

2. Die Stromazellen haben histogenetisch zweierlei Ursprung, erstens aus Marksträngen, zweitens aus Keimepithel. Sic sind also im Ganzen ausschliesslich von epithelialer Abkunft.

3. Die Bildung der Stromazellen geschieht einfach dadurch, dass ler Markstrang sein Element abbindet und an das Interstitium abgibt. Letzteres tritt bei neugeborenen und allen jüngeren Hündinnen meist mehr oder minder deutlich hervor; bei den Erwachsenen dagegen ist es nur zeitweise zu erkennen.

4. Interstitielle Zellen resp. Drüsen sind beim Hund nichts anderes als die Stromazellen selbst oder deren Ansammlungen, die alle in. Tätigkeit gesetzt sind. Sie haben drüsige Struktur, müssten demnach sekretorisch tätig sein.

5. Die interstitiellen Zellen resp. Drüsen kommen nur zcitweise zum Vorschein, nämlich eimmal in einem jugendlichen Alter von ctwa zwei bis 6 Monaten, damn bei Erwachsenen unter Umständen. Sie gehen nach der Funktion fast völlig verloren.

6. Der Markstrang bleibt jederzeit bestehen. Er gibt einerseits den Stroma- resp. interstitiellen Zellen ihren Ursprung, hat andererseits zu ciner bestimmten Zeit mit der Follikelbildung etwas zu tun.

\section{Literatur.}

1. Benthin, W., 1910. Irch. f. Gynaekol. Bd. 91. S. 499.

2. Bühler, 1906. Handb. d. vergleich. u. experiment. Entwickel. d. Wirbeltiere. Herausgegeb, von Hertwig. Bd. 3. S. 716.

3. Clark, J. G., 1898. Arch. f. Anatom. u. Entwick.-geschich. S. 95.

4. Cohn, F., 1903. Arch. f. mikrosk. Anat. u. Futw.-geschichte. Bd. 62. S. 745.

5. Fraenkel, I., 1905. Arch. f. Gynaecol. Bd. 75. S. 443.

6. Halban u. Seitz., 1923. Biologie u. Pathologie des Weibes.

7. Hartmann, H., 1926. Arch. f. Gynäk. Bd. 128. S. 1.

8. Harz, N., 1883 . Arch. f. mikrosk. Anatom. Bd. 2.2. S. 374.

9. Kölliker, 1898-1900. Inatom. Anzeig. Bd. 22. ‥ 149. 
Der Ursprung der interstitiellen Zellen des Ovariums beim Hunde.

10. Kölliker, 1899. Handbuch d. Gewebslehre. Bd. 3. S. 506.

11. Limon, 1902. Referiert in Schwalbes Jahresbericht. N. F. Bd. 7. 3. Lbteil. S. 387.

12. Meyer, H., 1913. Arch. f. (ignäk. Bd. 100. S. 1.

13. I ey, R., 1926. Arch. f. Gynäk. Bd. 128. S. 177.

14. Nagel, W., 1898. Ergebn. f. Anatom. u. Entwickl.-geschichte. B. 8. S. 210.

15. Rabl, H., 1899. Arch. f. mikr. Anatom. Bd. 54. S. 421.

16. Schaeffer, A., 1911. Irch. f. Gynäk. Bd. 94. S. 491.

17. Schmal\%, R., 1911. Handlb. d. vergleich. mikr. Anatom. d. Haustiere. Herausgegeb. v. W. Ellenberger. Bd. 2. S. 496.

18. Schottländer, J., 1891. Arch. f. mikr. Anatom. Bd. :37. S. 19:.

19. — 1893. Arch. f. mikr. Anatom. Bd. 41. S. 219.

20. Schulin, K., 1881. Arch. f. mikr. Anatom. Bd. 19. S. 442.

21. Seitz, I., 1906. Arch. f. Gynäk. Bd. 77. S. 203.

22. Stratz, C. H., 1898. Zeitschr. f. Geb. u. Gynäk. Bd. 38. S. 146.

29. Tsukaguchi, R., 1912. Berichte d. 20. Ansamml. d. japanisch. anat. Gesellschaft in Okayama.

24. Wallart, J., 1907. Arch. f. Gynäk. Bd. 81. S. 271.

25. Wolz, E., 1912. Arch. f. Gynäk. Bd. 97. S. 131. 